\title{
Substâncias Húmicas: Possibilidade de um Novo Agente Terapêutico
}

\author{
Natália Noronha Ferreira* \\ Ademir dos Santos** \\ Maria Lucia Ribeiro* \\ Luciana Camargo de Oliveira** \\ Wander Gustavo Botero*** \\ Julio Cesar Rocha**
}

\section{RESUMo}

Substâncias húmicas ( $\mathrm{SH}$ ) são agregados moleculares heterogêneos, possuem estrutura indefinida e constituema principal fração da matéria orgânica natural. Devido ao elevado número de grupos funcionais presentes em sua estrutura, podem atuar como agentes complexantes, influenciando diretamente o transporte, acúmulo, biodisponibilidade e toxicidade de diferentes substâncias. Dentre os contaminantes ambientais, se destacam os metais, pela sua ampla aplicabilidade em diferentes setores e por não sofrerem degradação química ou biológica. O tratamento de intoxicações por metais potencialmente tóxicos em seres humanos vem sendo realizado por agentes complexantes, como o etilenodiaminotetraácetico (EDTA) e os $\alpha$-aminoácidos. Entretanto, algumas limitações, como a falta de seletividade do EDTAe o elevado custo dos $\alpha$-aminoácidos, têmincentivado a busca por outras substâncias quelantes. Nesse sentido, este artigo aborda as principais propriedades descritas na literatura que tornam as substâncias húmicas uma interessante alternativa como agente terapêutico, em casos de intoxicações por metais potencialmente tóxicos.

Palavras-chave: Substâncias húmicas; Metais potencialmente tóxicos; Agentes quelantes.

\footnotetext{
*Centro Universitário de Araraquara - Uniara. Programa de mestrado em Desenvolvimento Regional e Meio Ambiente. Rua Carlos Gomes, 1338 - Centro. Araraquara-SP. E-mail: noronhanat@ hotmail.com. **Instituto de Química-Unesp. Rua Francisco Dogni s/n. - Quitandinha. Araraquara-SP. E-mail: iqunespambiental@gmail.com.

***Universidade Federal de Alagoas/Ufal. Av. Manoel Severino Barbosa s/n. - Bom Sucesso. ArapiracaAL. E-mail: wander_botero@hotmail.com.
} 


\section{INTRODUÇÃO}

Intoxicações agudas e crônicas por metais potencialmente tóxicos em seres humanos têm sido relatadas na literatura (SILVA et al., 2007). O tratamento médico comum, nesses casos, envolve a administração de compostos que sejam capazes de reter o metal, denominados agentes quelantes ou complexantes. No entanto, os agentes disponíveis no mercado parecem apresentar algumas limitações que tornam seu uso restrito. Entre essas limitações estão principalmente o elevado custo, a falta de seletividade e as dificuldades encontradas na administração desses compostos. Nesse contexto, a busca por novos agentes complexantes, seletivos, de baixo custo e fácil administração, é cientificamente relevante. Estudos descritos na literatura revelam algumas características das substâncias húmicas $(\mathrm{SH})$ que suprem as necessidades essenciais na busca de um novo agente terapêutico quelante. Assim, apesar da necessidade de estudos que comprovem a sua eficiência, as $\mathrm{SH}$ podem representar uma alternativa interessante para o tratamento de intoxicações por metais.

\section{SubSTÂNCIAS hÚMICAS}

As SH são os principais componentes resultante da decomposição da matéria orgânica natural, cuja investigação se iniciou há muitos anos, principalmente devido à grande correlação entre fertilidade do solo e a produtividade na agricultura (ABATE, 1998).

De Saussure (1982) introduziu o termo húmus para descrever o material orgânico de coloração escura originado do solo. Percebeu que o húmus era derivado de resíduos vegetais, sendo rico em carbono, mas pobre em hidrogênio e oxigênio. Os principais constituintes da matéria orgânica são carbono (52\%-58\%), oxigênio (34\%$39 \%)$, hidrogênio $(3,3 \%-4,8 \%)$ e nitrogênio $(3,7 \%-4,2 \%)$.

Toda matéria orgânica encontrada em solos, turfas e sedimentos consiste em uma mistura de compostos que se encontram em diferentes estágios de decomposição. Essa matéria orgânica é diferenciada em húmus, substâncias húmicas e substâncias não húmicas. Ao contrário das substâncias húmicas, as não húmicas possuem natureza definida, como, por exemplo, os aminoácidos, proteínas e ácidos orgânicos (STEVENSON, 1994).

As SH compreendem uma classe de macromoléculas com variações em suas propriedades moleculares (ROCHA\& ROSA, 2003). Durante a sua extração, dividemse em três principais frações: os ácidos húmicos - fração das SH solúvel em meio alcalino diluído e que precipita pela acidificação do extrato alcalino -, os ácidos fúlvicos (AF) - que permanecem em solução quando o extrato alcalino é acidificado -, e a humina - fração não extraída por ácido ou álcali diluído (HAYES, 1998). Um esquema que representa o fracionamento das SH está representado na Figura 1. 


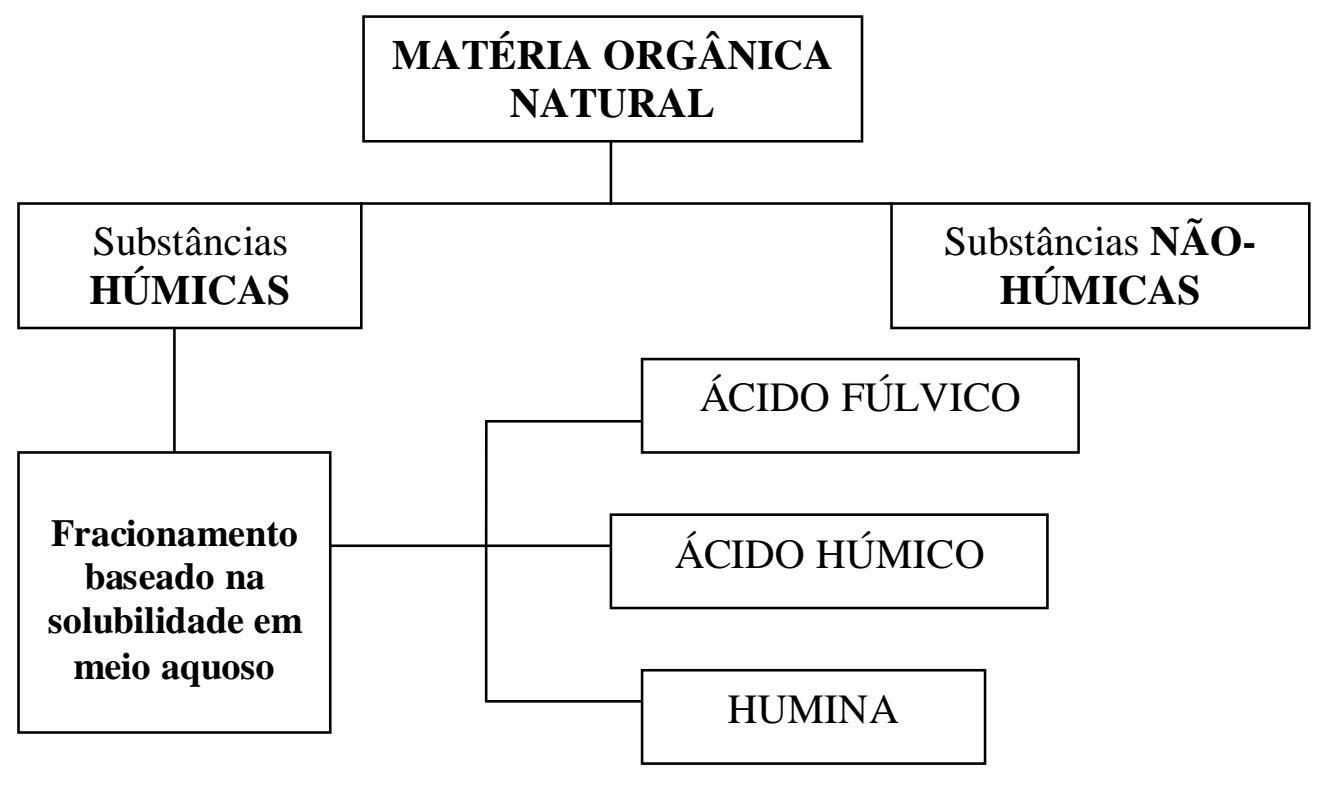

Figura 1. Fracionamento do material orgânico das substâncias húmicas. (Adaptado de ROSA, 1998).

Apesar de vários estudos, a determinação da estrutura das $\mathrm{SH}$, bem como a bioquímica de sua formação, constitui ainda hoje um dos aspectos pouco compreendidos da química do húmus. Vários trabalhos foram escritos sobre esses temas, entre os quais se destacam: Gieseking, 1992; Stevenson 1982; Budziak et al., 2004; Da Silva \& Mendonça, 2001; Piccolo, 2002; Piccolo \& Spiteller, 2003.

Várias são as teorias sobre a formação das $\mathrm{SH}$. A denominada teoria clássica Waksman (1982) propõe que as SH são ligninas modificadas, mas a maioria dos pesquisadores acredita em um mecanismo relacionado com a formação de quinonas (ROCHA \& ROSA, 2003). Malcolm (1990) afirma que a lignina não é o principal precursor de $\mathrm{SH}$ de solo. Além disso, mostra que há grandes diferenças estruturais entre SH de diferentes origens, como, por exemplo, de solo, rios e mar.

Em razão da natureza heterogênea e complexa das SH, apesar de todos os esforços dos pesquisadores da área, pouco se sabe ainda sobre a sua estrutura química. Na literatura existem várias propostas estruturais para as $\mathrm{SH}$ (KONONOVA, 1966; SCHNITZER \& KHAN, 1978; STEVENSON, 1985), entretanto, de acordo com Stevenson (1985), nenhuma parece ser inteiramente satisfatória devido à complexidade estrutural e, principalmente, pela falta de uma identidade estrutural genérica, que é fortemente influenciada pelo mecanismo de decomposição. 
Estudos recentes, baseados em cromatografia e eletroforese capilar, têm sugerido um novo conceito em relação às características estruturais das SH. Piccolo (2002) propôs que as SH são associações supramoleculares de moléculas heterogêneas relativamente pequenas, que se mantêm agregadas por interações fracas, como as de Van der Waals e pontes de hidrogênio. Assim, os ácidos fúlvicos são originados, principalmente, pela associação de pequenas moléculas que apresentam grupos funcionais ácidos, os quais mantêm seus constituintes solúveis em qualquer faixa de pH. Já os ácidos húmicos são originados pela associação de compostos hidrofóbicos, que são estáveis em $\mathrm{pH}$ neutro em consequência das forças dispersivas hidrofóbicas (AZEVEDO \& NOZAKI, 2008). Aquímica supramolecular vem se desenvolvendo a partir dos avanços de conhecimento sobre a química da funcionalidade de espécies bioquímicas. Os novos materiais produzidos por meio desse conhecimento são a base do desenvolvimento da engenharia molecular e da nanotecnologia (OLENDZKI, 2006).

Entretanto, mesmo com as contradições existentes quanto ao modelo estrutural, algumas características das SH já estão bem definidas: as frações de ácido húmico e ácido fúlvico são misturas heterogêneas de moléculas polidifusas, com intervalos de massa molar variando de algumas centenas até milhões (STEVENSON, 1985); há variação da razão entre ácido húmico e ácido fúlvico em função do tipo de solo, e essa razão está associada ao grau de humificação do mesmo (ROCHA \& ROSA, 2003); os ácidos húmico e fúlvico apresentam alto teor de grupos funcionais contendo oxigênio, tais como carboxilas, hidroxilas fenólicas e alcoólicas e carbonilas de vários tipos (STEVENSON, 1985).

IMPORTÂNCIA DAS SUBSTÂNCIAS HÚMICAS NO AMBIENTE E INTERAÇÕES COM ESPÉCIES METÁLICAS

As SH representam a principal forma de matéria orgânica (MO) distribuída no planeta. Elas são encontradas não apenas em solos, mas também em águas naturais, turfas, pântanos, sedimentos aquáticos e marinhos. Aquantidade de carbono presente na Terra na forma de $\mathrm{SH}\left(6010^{11} \mathrm{t}\right)$ excede aquela presente em organismos vivos (7 $10^{11}$ t) (STEVENSON, 1994).

As SH são ambientalmente importantes pelas seguintes razões:

$\checkmark$ dependendo das condições do meio possuem características oxirredutoras, influenciando a redução de espécies metálicas para a atmosfera (ROCHA et al., 2009).

$\checkmark$ de acordo com Wershaw (1993), propriedades físico-químicas do solo e de sedimentos são largamente controladas pelas substâncias húmicas.

$\checkmark$ influenciam a biodisponibilidade de metais do solo para plantas e/ou organismos 
da micro e macrofauna.

$\checkmark$ influem na toxicidade de alguns metais, formando complexos com diferentes labilidades relativas (ROCHA et al., 1997a,b), reduzindo a toxicidade de certos metais, como $\mathrm{Cu}^{+2}$ e $\mathrm{Al}^{+3}$, para organismos aquáticos e solos (SANTOS \& RODELLA, 2007).

$\checkmark$ influem no transporte, acúmulo e concentração de espécies metálicas no ambiente. (AGUIAR et al., 2007).

Assim, devido principalmente à sua propriedade quelante e à sua ação complexante, as $\mathrm{SH}$ podem atuar como um sorvedouro de diferentes espécies no ambiente, inclusive poluentes.

Dentre esses poluentes, os metais representam um grupo especial, pois seu comportamento é diferente das demais substâncias tóxicas. Os metais estão presentes nos mais diversos compartimentos ambientais, possuem grande aplicabilidade em diversos setores e não sofrem degradação química ou biológica. Portanto, são infinitamente não degradáveis, de maneira que podem acumular-se nos organismos vivos, onde manifestam a sua toxicidade (BAIRD, 2002). Os efeitos que provocam na saúde estão ligados ao seu transporte ambiental, que é realizado por ar, água, solo, alimentos e por meio das alterações na apresentação bioquímica desses elementos (ROZEMA, 1998).

A presença de metais potencialmente tóxicos no ambiente aquático em concentrações elevadas causa a mortalidade de peixes e seres fotossintetizantes (SEIXAS et al., 2007). No solo, promovem a redução da fertilidade e prejudicam o desenvolvimento das plantas. Sua introdução no organismo humano via cadeia alimentar pode provocar inúmeras doenças, pois apresentam efeito cumulativo, podendo causar até mesmo a morte (CAMPOS et al., 2009).

\section{TOXICIDADE POR METAIS}

A contaminação ambiental por metais se dá tanto por fontes naturais como pela atividade industrial, que cresce a cada ano.

Os dados sobre o número de áreas contaminadas por metais pesados, no Brasil, não são precisos (CRESCÊNCIO JR, 2008). Dentre todas as agências estaduais do meio ambiente, somente a Companhia Ambiental do Estado de São Paulo (CETESB) apresenta um cadastro atualizado de áreas contaminadas. Atualmente, existem no Estado de São Paulo 2.272 áreas contaminadas. Desse total, cerca de 10\% (276) está contaminado por metais pesados (CETESB, 2006).

As intoxicações causadas pelos metais podem ser classificadas em três categorias:

$\checkmark$ Intoxicacões agudas: são as que ocorrem após intensa exposição, em um breve período de tempo, a substâncias de extrema ou alta toxicidade. Os sintomas 
são nítidos, aparecem rapidamente e a quantidade da substância absorvida determina a gravidade da intoxicação.

$\checkmark$ Intoxicacões subagudas: aparecem mais lentamente por meio de sintomas subjetivos e vagos, e ocorrem em consequência da exposição a substâncias moderadamente ou altamente tóxicas.

$\checkmark$ Intoxicacões crônicas: são as que ocorrem tardiamente, após meses ou anos de pequena ou média exposição a uma substância tóxica. Apresentamum quadro clínico indefinido que dificulta o estabelecimento da causa (LEVIGARD, 2001).

A toxicidade por metais, antigamente, preocupava apenas pelas manifestações agudas, como cólicas abdominais, diarreias com sangramentos, ou ainda pelo comprometimento urinário, que pode ser causado, por exemplo, pela ingestão de sublimado corrosivo de mercúrio. Atualmente, os estudos da literatura estão direcionados para os efeitos sutis e de longo prazo, nos quais a relação causa-efeito não é tão evidente e, muitas vezes, subclínica (LEVIGARD, 2001; FERREIRA et al., 2008; SILVA et al., 2007; JUNIOR \& ALVES, 2006).

O mecanismo de intoxicação por íons metálicos pode ser agrupado em duas classificações: na primeira ocorre o desequilíbrio eletrolítico, absorção dos sítios negativos das enzimas e desequilíbrio osmótico. Esse é o caso de intoxicações causadas por lítio $\left(\mathrm{Li}^{+}\right)$, sódio $\left(\mathrm{Na}^{+}\right)$, potássio $\left(\mathrm{K}^{+}\right)$e outros íons metálicos semelhantes. No segundo caso, acontece a formação de complexos de grande toxicidade ao organismo vivo. Alguns íons metálicos que formam compostos de coordenação como enxofre e o oxigênio possuem tendência a acumularem-se no organismo (TROMBE, 1994).

O tratamento da toxicidade do metal é essencial em situações agudas, especialmente para os metais que são cumulativos. A dose ou nível de exposição a determinado metal deve ser considerado importante.

A definição mais precisa de dosagem tóxica é a quantidade de metal que, dentro das células ou órgão, manifestam efeito toxicológico. Para determinação dessas dosagens, geralmente se faz uso de amostras biológicas do tipo sangue, urina ou cabelos (ROZEMA, 1998).

A toxicidade nas células está diretamente ligada à biodisponibilidade. A forma química, assim como o tipo de ligação que o metal realiza no organismo, também são fatores críticos. Os compostos orgânicos de cadeias longas são, na sua maioria, lipossolúveis e capazes de transpor as membranas biológicas inalterados pelo meio adjacente.

Existem alguns princípios gerais que levam à compreensão da fisiopatologia da toxicidade do metal. A maioria dos metais envolve sistemas múltiplos de órgãos e seus alvos para toxicidade são processos bioquímicos específicos, membranas das 
células ou, ainda, organelas. Os metais potencialmente tóxicos podem ser substituídos pelos metais essenciais nas enzimas, em razão de suas características similares de ligação e, dessa forma, promovem o bloqueio natural da enzima. As células que promovem o transporte desses metais são suscetíveis à toxicidade, tais como as gastrointestinais, as do fígado ou as células tubulares dos rins.

A ocorrência da toxicidade é afetada por inúmeros fatores exógenos, como idade, alimentação e interações ou exposições concorrentes com outros metais tóxicos. Alguns alimentos são capazes de atuar como redutores da capacidade tóxica de alguns metais. A vitamina $\mathrm{C}$ (ácido ascórbico), por exemplo, reduz absorção de cádmio e chumbo pelo organismo, por meio da competição desses metais com os íons ferro (ROZEMA, 1998).

O método mais seguro de reduzir a exposição a metais tóxicos é estudando-os, compreendendo os processos de exposição ou, ainda, buscando alternativas para minimizar os efeitos da exposição no organismo humano.

\section{Metais POTENCIALMENTE TóXICOS}

Em Química, o termo metal potencialmente tóxico se refere a uma classe de elementos químicos, muitos dos quais extremamente perigosos aos seres humanos. Dentre esses metais, o chumbo $(\mathrm{Pb})$ é um dos que apresentam o maior risco ambiental, em razão de seu uso intenso, toxicidade e ampla distribuição (BAIRD, 2002).

Os reservatórios naturais vêm sendo depositários de uma variedade de subprodutos provenientes da atividade antrópica. A presença de elementos potencialmente tóxicos é responsável por efeitos adversos no ambiente, com repercussão direta na saúde pública. A introdução de metais potencialmente tóxicos nos sistemas aquáticos e em outros compartimentos ambientais ocorre naturalmente, por meio de processos geoquímicos e no intemperismo; a contribuição decorrente da atividade humana é um reflexo de sua ampla utilização pela indústria (CAMPOS et al., 2009).

Diversos metais desempenham no organismo humano funções indispensáveis ao seu estado fisiológico normal. No entanto, muitos desses mesmos metais podem acumular-se no organismo, causando uma série de problemas funcionais ou estruturais, que podem adquirir natureza grave (BAIRD, 2002).

Alumínio, níquel, chumbo e cromo são metais potencialmente tóxicos que possuem ampla aplicabilidade em diversos setores industriais. A seguir, estão descritas algumas características, propriedades, ocorrência e o papel fisiológico ou patológico que esses desempenham no organismo humano.

O alumínio é o elemento metálico mais abundante da crosta terrestre na forma de óxido de alumínio $\left(\mathrm{Al}_{2} \mathrm{O}_{3}\right)$. Sua leveza, condutividade elétrica, resistência à corrosão 
e baixo ponto de fusão the conferem uma multiplicidade de aplicações, especialmente nas soluções de engenharia aeronáutica. Considerando a quantidade e o valor do metal empregado, o uso do alumínio excede o de qualquer outro metal, exceto o aço. O elemento, embora muito abundante na natureza, parece não apresentar nenhuma função biológica significativa (FERREIRA et al., 2008).

O alumínio é liberado no meio ambiente por processos naturais de erosão do solo, erupções vulcânicas ou ainda, por ações antropogênicas. A fonte mais importante para a obtenção do metalé a bauxita, com uma concentração próxima a 55\% de óxido de alumínio. A maior parte da ingestão de alumínio provém de alimentos contaminados, água contaminada (sais de alumínio são muito utilizados como coagulantes para redução da matéria orgânica, turbideze presença de microrganismos durante o tratamento de água) e alimentos que o utilizam como conservante ou corante. Algumas pessoas manifestam alergia ao metal, desenvolvendo dermatites de contato ou problemas digestivos ao ingerir alimentos cozidos emrecipientes contendo alumínio (DANTAS et al., 2007).

Apesar disso, o alumínio não é considerado tóxico como os metais pesados, ainda que existam evidências de toxicicade quando ingerido em grandes quantidades. A exposição a altas concentrações pode causar problemas de saúde, principalmente quando na forma de íons em que ele é solúvelem água. Alguns estudos sugerem que a ingestão excessiva desse elemento pode estar diretamente relacionada com o mal de Alzheimer. (FERREIRA et al, 2008).

Um estudo realizado em 1965 promoveu a inoculação de sulfato de alumínio em coelhos. O procedimento resultou em degeneração neurofibrilar de semelhança significativa com a neurodegeneração fibrilar que ocorre na doença de Alzheimer. Ainda que essa hipótese não possua uma comprovação conclusiva, diversos estudos apontam o alumínio como um dos fatores de risco para Alzheimer (FERREIRAet al, 2008).

A ingestão do metal pode acontecer pela alimentação, pelo ar e pelo contato com a pele. Em concentrações altas pode levar a sérios problemas de saúde como: demência, danos ao sistema nervoso central, perda de memória, surdez, fortes tremores, dores musculares, cólicas, fraqueza, inapetência e impotência. A inspiração de alumínio em pó, em fábricas onde o elemento é utilizado no processo de produção, pode levar à fibrose pulmonar e a outros danos ao pulmão. Este efeito, conhecido como mal de Shaver, é complicado pela presença no ar de sílica e óxido de ferro. Na diálise renal ele pode penetrar nos rins e causar danos irreversíveis (ABAL, 2009).

No Brasil, a Agência Nacional de Vigilância Sanitária (Anvisa), órgão vinculado ao Ministério da Saúde, é a responsável pela regulamentação do uso de alumínio em 
utensílios metálicos, embalagens e equipamentos, por meio da Resolução Anvisa RDC n. ${ }^{\circ}$ 20/2007. De acordo com a agência, o alumínio e seus compostos são muito pouco absorvidos pelo organismo e o corpo humano apresenta uma barreira (intestinal) ao que é ingerido, reduzindo sua absorção.

O níquel é um metal de transição, condutor de eletricidade e calor, dúctil e maleável, encontrado em diversos minerais e em meteoritos (formando liga metálica com o ferro). Aproximadamente $65 \%$ do níquel consumido é empregado na fabricação de aço inoxidável para formação e estabilização da austenita, promovendo um aumento considerável na resistência mecânica, e outros $12 \%$ em superligas de níquel. O restante, $23 \%$, é utilizado na produção de outras ligas metálicas, baterias recarregáveis, cunhagem de moedas, revestimentos metálicos e fundição (BUBANI et al., 2007).

Ao contrário do alumínio, o níquel apresenta um importante papel biológico. Muitas, porém não todas, das enzimas hidrogenases existentes no organismo humano contêm níquel, especialmente aquelas cuja função é oxidar o hidrogênio. O níquel comporta-se como a parte ativa da enzima, sofrendo mudanças no seu estado de oxidação no momento em que exerce sua atividade biológica. Além disso, também possui ação catalisadora sobre diversas enzimas, podendo ativar ou inibir reações enzimáticas de importância crucial nos seres humanos. Ainterferência em algumas reações dessa natureza podem resultar em efeitos deletérios severos (ICZ, 2009).

No entanto, apesar do papel biológico que exerce no organismo, a necessidade de ingestão de níquel nos seres humanos é extremamente pequena: cerca de $5 \mu \mathrm{g} /$ dia, ainda que a estimativa de consumo diária esteja em torno de $150 \mu \mathrm{g} / \mathrm{dia}$. Apesar de essencial, o níquel, quando ingerido em quantidades superiores, pode ocasionar diversos problemas à saúde humana, sendo até mesmo, em algumas circunstâncias, um veneno forte (E-ESCOLA, 2008).

Em contato com a pele, é capaz de causar dermatites, embora os efeitos sejam variados, de acordo com a suscetibilidade das pessoas. Dentro do organismo humano, o níquel liga-se à albumina e é transportado na corrente sanguínea, acumulando-se em alguns órgãos, principalmente nos rins, fígado e pulmões. Amaneira mais comum de sua excreção é pela urina (ALI et al., 1987).

Uma das formas mais tóxicas em que o elemento pode se apresentar é o tetracarbonilo de níquel $\mathrm{Ni}(\mathrm{CO})_{4}$, gás extremamente tóxico, gerado durante o processo de obtenção do metal. A inalação do composto, mesmo em pequenas quantidades, é potencialmente fatal (DUARTE, 2004).

O homem está exposto ao níquel pelo ar que respira, pela água (ingerida e contato), pelo fumo dos cigarros, e ingere-o diariamente em alimentos como cocos, alguns frutos secos, nabos, chocolate, gorduras e flocos de aveia, que têm altos níveis do elemento em sua constituição. As quantidades ingeridas, diariamente, são 
cerca do triplo do que é necessário, mas são níveis seguros. Mesmo em casos, devido à dieta, em que os valores atingem os 100-300 $\mu \mathrm{g} /$ dia, não surgem graves problemas de toxicidade. Os próprios utensílios de cozinha e alguns detergentes libertam níquel, contribuindo, significativamente, para a sua ingestão diária. Outra fonte é o cigarro, que acumula diretamente em nível pulmonar 2-23 $\mu$ g níquel/dia (40 cigarros). O níquel proveniente dessa via pode levar à irritação respiratória e até mesmo a pneumonias (JUNIOR \& ALVES, 2006).

O cromo é um metal de transição, duro, frágil, de coloração cinza semelhante ao aço e muito resistente à corrosão. Seu maior estado de oxidação é +6, ainda que estes compostos sejam muito oxidantes. Os estados de oxidação +4 e +5 são pouco frequentes, enquanto os estados mais estáveis são +2 e +3 . É empregado principalmente em metalurgia, para aumentar a resistência à corrosão e dar um acabamento brilhante na fabricação de aço inoxidável, pigmentos, cerâmica, borracha, fitas magnéticas e em curtumes (FREITAS, 2006).

Em sistemas fisiológicos, o cromo pode ser encontrado nos estados de oxidação III-VI. Os compostos contendo Cr (VI), Cr(V) ou Cr (IV) são agentes oxidantes relativamente fortes em $\mathrm{pH}$ fisiológico, e a estabilidade dos mesmos depende do $\mathrm{pH}$ e da concentração dos agentes redutores (FERREIRA, 2002). Em seu estado de oxidação trivalente, atua como um elemento essencial no metabolismo de carboidratos e dos lipídios, estando a sua função diretamente relacionada com o mecanismo de ação da insulina (SANO et al., 1999).

A quantidade de cromo III recomendada para a ingestão diária é de 50 a $200 \mu \mathrm{g}$ e sua carência na alimentação pode causar ansiedade, fadiga e problemas de crescimento, além de diabetes e complicações cardiovasculares. Em contraposição, seu excesso pode causar dermatites, úlcera, problemas renais e hepáticos (MERTZ, 1993). Ao contrário do íon trivalente, no estado de oxidação VI o cromo é classificado como composto mutagênico e carcinogênico em animais (FERREIRA, 2002).

A toxicidade do cromo (VI) pode ocorrer de maneira aguda, após ingestão, levando à inflamação do tubo digestivo, seguida de necrose extensa. Os sintomas característicos do envenenamento por exposição aguda são vômitos, diarreias, diátese hemorrágica e perda de sangue no trato gastrointestinal, causando choque cardiovascular. Compostos de cromo, por sua vez, produzem reações cutâneas, nasais, broncopulmonares, renais, gastrointestinais e carcinogênicas. As cutâneas são caracterizadas por irritação no dorso das mãos e dos dedos, podendo transformar-se em úlceras. As lesões nasais iniciam-se com um quadro irritativo inflamatório, supuração e formação crostosa (ZINI et al., 2009). Em níveis broncopulmonares e gastrointestinais, produzem irritação bronquial, alteração da função respiratória e úlceras gastroduodenais. (FERREIRA et al., 2006). 
O chumbo é um metal potencialmente tóxico (densidade relativa de $11,4 \mathrm{a} 16^{\circ} \mathrm{C}$ ), de coloração branca-azulada que, exposto ao ar, adquire coloração acinzentada. Trata-se de um metal altamente macio, maleável, com baixa condutividade elétrica e altamente resistente à corrosão.

O chumbo pode ser um contaminante ambiental, e as concentrações no meio ambiente cresceram de acordo com o aumento do seu uso industrial. Após a Revolução Industrial, as concentrações desse elemento no ambiente se elevaram de forma alarmante, principalmente em decorrência da introdução de compostos orgânicos de chumbo (chumbo tetraetila) como aditivo para gasolina. Nos últimos anos, observa-se uma mudança quanto a sua utilização. Seu emprego como antidetonante na gasolina e em tintas tem diminuído bastante, principalmente pela regularização de leis que proíbem ou mesmo restringem este uso. No entanto, seu emprego em diferentes processos industriais tem aumentado significamente (MAVROPOULOS, 1999).

Existem duas classes de compostos de chumbo: os inorgânicos, que são os formados por sais e óxidos de chumbo, e os orgânicos, que são o chumbo tetraetila e o chumbo tetrametila. Os compostos orgânicos são lipossolúveis e podem ser absorvidos pela pele e por via respiratória, promovendo transtornos nervosos no organismo humano. Sua absorção pelo corpo humano é lenta e depende não só da dose como também de fatores como a idade do indivíduo, condições fisiológicas e nutricionais e, possivelmente, de fatores genéticos. Pela via digestiva ocorre a maioria das intoxicações domésticas. A absorção dá-se no intestino delgado e depende dos níveis de cálcio, magnésio, ferro, fósforo e vitamina D na dieta humana (LARINI, 1993).

Dietas pobres em cálcio, ferro e fósforo podem aumentar a absorção do chumbo pelo trato intestinal, bem como aumentar a deposição desse metal nos ossos (CORDEIRO, 1995). Quando absorvido pelo organismo, não se apresenta de maneira homogênea. No sangue ele se associa aos eritrócitos e é distribuído aos tecidos moles. Cerca de $90 \%$ do chumbo encontrado no organismo está retido nos ossos sob a forma de trifosfato. No sangue, possui uma meia vida de aproximadamente 36 dias, enquanto nos ossos esse período é prolongado para cerca de 30 anos (LARINI, 1993).

Cerca de $90 \%$ do chumbo ingerido e não absorvido é excretado pelas fezes, sob a forma de sulfetos insolúveis. Aproximadamente $75 \%$ é eliminado pela urina. Apesar do nível de chumbo na urina ter sido umindicador de exposição ao metal, é importante ressaltar que essa concentração não representa com fidelidade o grau de absorção, já que os rins excretam quantidades elevadas de chumbo somente quando a concentração do metal no sangue for alta. Para pequenas concentrações, a 
determinação da concentração de chumbo na urina será útil quando acompanhada de outros parâmetros. Quando administrado em pequenas quantidades, pode também ser eliminado através do suor, saliva, unhas e cabelos. (MAVROPOULOS, 1999).

Os estados de oxidação do chumbo variam de acordo com os compostos, podendo ser $+2 \mathrm{ou}+4$. Os compostos de chumbo são, de uma maneira geral, nocivos para os animais (QUINTELAS, 2000). A principal manifestação clínica do efeito da intoxicação pelo metalé a anemia, que ocorre somente com altos níveis de exposição, o que atualmente não é muito comum. O chumbo inibe várias etapas na biossíntese do grupo heme da hemoglobina. A inibição das enzimas ácido delta-aminolevulínico desidratase (ALA-D) e da hemessintetase já foi caracterizada, enquanto estudos in vitro indicam um aumento da atividade para a enzima ácido delta-aminolevulínico sintetase (ALA-S) durante a exposição ao metal. Devido à inibição da hemessintetase, última enzima na biossíntese do heme, o ferro da molécula de protoporfirina IX é substituído pelo zinco dos reticulócitos e, no lugar de se produzir heme, forma-se a protoporfirina zinco.

No sistema nervoso, os principais efeitos dos compostos de chumbo por exposições crônicas são encefalopatias com irritabilidade, cefaleia, tremores musculares, alucinações, perda da memória e do aprendizado. Além disso, pode ocorrer hiperestesia e analgesia da área afetada. No sistema renal, os efeitos podem ser frutos tanto de exposições agudas como de exposições crônicas. Em adultos e em crianças, o chumbo é capaz de promover danos reversíveis no túbulo renal. No sistema gastrintestinal, os sintomas são mais evidentes no caso de intoxicações severas, podendo ocasionar constipação, diarreias e gastrites (MAVROPOULOS, 1999).

A possibilidade de o chumbo causar câncer em seres humanos não é bem conhecida. Entretanto, pesquisas revelam que roedores, quando expostos a altas doses do metal, desenvolvem tumores. O Departamento de Saúde e Serviços Humanos dos Estados Unidos tem constatado a possibilidade dos acetatos e fosfatos de chumbo serem carcinogênicos (NASCIMENTO et al, 2006). Um estudo realizado por Larini (1993) demonstrou que, em animais, o elemento é capaz de promover tumores malignos e benignos.

Os limites de tolerância biológicos (LTB) propostos para a intoxicação pelo metal variam. Os LTB são fixados de acordo com investigações científicas e devem estar relacionados com a política de saúde de cada país (CORDEIRO, 1995).

Fármacos Utilizados Na terapêutica de intoxicaÇões por metais POTENCIALMENTE TÓXICOS

Quando os metais potencialmente tóxicos como o chumbo são analisados de um ponto de vista bioquímico, o mecanismo de sua ação tóxica está diretamente 
ligado a sua forte afinidade com as sulfidrilas (-SH), que ocorrem comumente em enzimas que controlam a velocidade de reações metabólicas e possuem importância crítica no organismo humano. Essas enzimas se ligam rapidamente aos cátions, principalmente de metais potencialmente tóxicos ingeridos, ou então às moléculas que contêm tal metal.

A ligação resultante da interação metal-enxofre da sulfidrila altera a enzima como um todo, impedindo que a mesma possa atuar com normalidade e, em consequência dessa interação, a saúde humana é afetada de maneira desfavorável e muitas vezes até fatal(BAIRD, 2002).

Agentes quelantes terapêuticos são compostos utilizados como antídotos para a ocorrência da toxicidade aguda por um metal. Ocorre uma rápida reação de um agente quelante e um metal através do sítio biológico; o complexo binário ou ternário resultante envolve o íon metálico, o agente e possivelmente outro ligante, formando um composto solúvel em água. Arota usual de eliminação desses metais do organismo é a urina, o que pode ser confirmado por meio da análise do metal nesta matriz biológica. Excreções via bile ou fezes são também importantes rotas de eliminação para alguns metais em particular (TROMBE, 1994).

O tempo é um fator muito importante em casos de intoxicações agudas por metais. Se a intoxicação é detectada com rapidez, os danos são menores; no entanto, quando um tratamento é iniciado tardiamente, os danos podem ser irreversíveis.

Um tratamento médico comum para o envenenamento agudo, causado por metais potencialmente tóxicos, consiste na administração de um composto que seja capaz de atrair o metal de maneira muito mais intensa que a enzima e, ainda, de tornar o complexo metal-composto solúvel, para que possa ser eliminado nas excretas do organismo.

Um dos compostos utilizados para o tratamento de envenenamento por mercúrio ou chumbo, e que obedece a esse princípio, é a Antilewisita Britânica ou 2,3Dimercaptopropanol-1 (BAL) (Figura 2). Sua molécula contém dois grupos -SH, que promovem a complexação do metal no organismo.

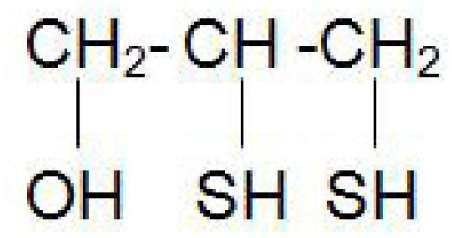

Figura 2. Estrutura da 2,3-Dimercaptopropanol-1. 
O BAL, primeiro agente quelante utilizado efetivamente em humanos, era capaz de proteger enzimas -SH no corpo dos gases à base de arsênio, usados em guerras. Os quelatos formados são suficientemente solúveis em água para serem excretados na urina. A molécula do BAL é lipossolúvel e tem a capacidade de remover depósitos de metais que geralmente não foram retidos por outros agentes quelantes (BAIRD, 2002).

Um outro composto, amplamente utilizado para o mesmo propósito, é o sal de cálcio do ácido etilenodiaminotetracético (EDTA), capaz de extrair e solubilizar uma variedade de íons metálicos (Figura 3) (JUNIOR \& ALVES, 2006).

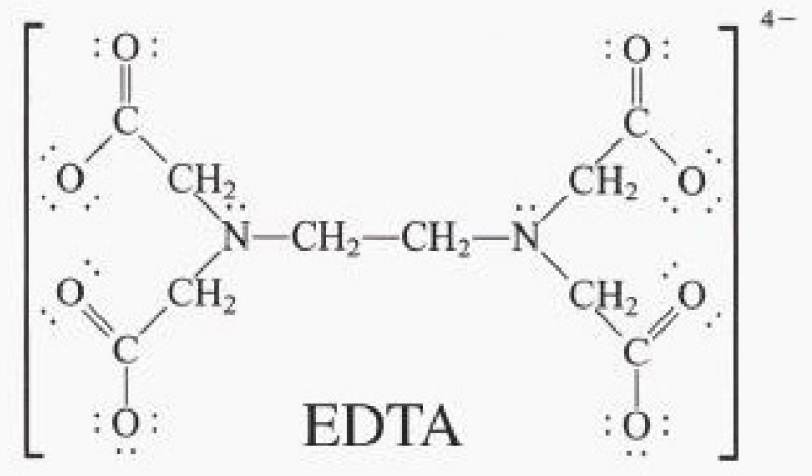

Figura 3. Estrutura do EDTA.

Os íons metálicos são complexados pelos dois nitrogênios e pelo oxigênio para formar um quelato que é imediatamente eliminado do organismo.

O uso mais comum é em casos de intoxicações por chumbo. No entanto, o EDTAé eficaz como quelante de ferro, cobre, zinco, alumínio, cádmio, arsênio, manganês e níquel. Portanto, o uso de EDTA, muitas vezes, se torna restrito, levando em conta que não se trata de um agente complexante seletivo, tornando necessária a ingestão de nutrientes para reposição logo após o seu uso (ROZEMA, 1998).

A forma mais comumente usada é o sal dissódico do EDTA, um pó branco, cristalino, solúvel em água, levemente solúvel em álcool e fracamente ácido. $\mathrm{O}$ EDTA controla os íons do metal bloqueando seus pontos reativos e evitando que os mesmos retomem sua atividade normal. Comumente se utiliza o sal de cálcio em vez do sal dissódico, visto que o íon cálcio não é lixiviado do organismo pelo EDTA(BAIRD, 2002).

Inúmeros fatores estão envolvidos na determinação da estrutura do complexo do EDTA com os íons dos metais. Entre esses fatores está o pH. Conforme o pH aumenta, os quelantes de EDTA se tornam mais estáveis, de modo que a molécula libera seus íons metálicos com menor facilidade. O segundo fator é a ligação direta 
do EDTA a vários cátions. A afinidade do cátion metálico com o agente quelante é dada pela reação de complexação. Metais potencialmente tóxicos, como cobre e chumbo, geralmente têm maior afinidade por agentes quelantes específicos. O terceiro fator é a concentração relativa dos vários metais.

Tendo em vista a interação do EDTAcominúmeros minerais, deve-se ter cuidado em repor os minerais essenciais quando os metais tóxicos foremeliminados. Amolécula de EDTA dissódico não é metabolizada no organismo ou reabsorvida pelos túbulos renais. Ele passa muito rapidamente para a urina transportando o íon metálico.

O EDTA administrado via oral (VO) vai ligar-se com os oligoelementos nutrientes no intestino, podendo inibir a absorção de minerais essenciais, o que pode ocasionar deficiências graves. Administrá-lo via intramuscular (IM) é contraindicado, pois pode causar necrose dos tecidos e dor intensa no local da administração. Portanto, a via de administração mais eficaz para que se tenham os benefícios clínicos atualmente reconhecidos é a intravenosa, embora tal exija inúmeros cuidados.

Os $\alpha$-aminoácidos são potenciais agentes de coordenação para íons metálicos, principalmente em razão da presença, em suas estruturas, dos grupos amino $\left(-\mathrm{NH}_{2}\right)$, carboxílico (-COO-) e carbonila (- $\mathrm{CH}=0$ ). Entretanto, apesar se serem mais seletivos que o EDTA, são extremamente caros e apenas aplicáveis na forma injetável (SANTOS, 2004).

Assim, a busca por agentes complexantes seletivos, preferencialmente de origem natural e de baixo custo, é cientificamente relevante. As substâncias húmicas parecem atender a essas exigências. Além de possuírem uma alta capacidade complexante, possuem seletividade para diferentes íons metálicos.

Um estudo realizado por SANTOS et al. (2007), no qual se efetuou a aplicação de doses crescentes de $\mathrm{SH}$ em ratos, revelou que as SH não são tóxicas quando administradas via oral até a dose de $512 \mathrm{mg} \mathrm{kg}^{-1}$ de peso corpóreo. Valores superiores a essa concentração impossibilitam esse tipo de administração, devido à consistência da solução preparada. Esses resultados reforçam a possibilidade do uso das substâncias húmicas como agente desintoxicante de metais em casos de intoxicações agudas.

\section{Considerações finais}

Considerando os agentes terapêuticos para intoxicações dispostos no mercado, e principalmente as dificuldades enfrentadas para a administração de cada um desses compostos, as substâncias húmicas apresentam vantagens (produto, natural, de baixo custo e de ampla disponibilidade) que a tornam uma alternativa extremamente interessante para sua utilização como agentes terapêuticos. Assim, são necessários estudos que garantam a eficiência e a segurança da aplicação terapêutica das substâncias húmicas. 


\section{REFERÊNCIAS}

ABAL. Associação Brasileira do Alumínio. Alumínio \& Saúde. Disponível em: http://www.abal.org.br/alusaude/produtoseguro.asp. Acessado em Agosto, 2009.

\section{ABATE, G. Isolamento, purificação e estudos de complexação de} substâncias húmicas. Dissertação de mestrado. Universidade de São Paulo. Instituto de Química. São Paulo,1998.

AGUIAR, A.; FERRAZ, A.; CONTRERAS, D.; RODRÍGUEZ, J. Mecanismo e aplicações da reação de fenton assistida por compostos fenólicos redutores de ferro. Química Nova, Vol. 30, No. 3, 623-628, 2007.

ALI, S. A.; GROTTI, A.; RISCALA, C.M. O níquel e suas ações sobre o organismo humano. Anais Brasileiro de Dermatologia. 62 (2). P. 85-96, 1987.

AZEVEDO, J. C. R. D.; NOZAKI, J. Análise de fluorescência de substâncias húmicas extraídas da água, solo e sedimento da lagoa dos patos - MS. Química Nova, Vol. 31, No. 6, 1324-1329, 2008.

BAIRD, C. Química Ambiental. 2.ed. Porto Alegre: Bookman, 2002.

BUBANI, F. C.; DECARLI, C. C. M.; MARQUES, D. C.; BARBOSA, C. A.; DINIZA. E.; MEI, P. R. Efeitos da adição de níquel em ligas ferrocromo.Parte I: propriedades mecânicas. Revista Escola de Minas, Ouro Preto, 60(1): 149154, jan. mar. 2007.

BUDZIAK,C. R.; MAIA, C. M. B. F.; MANGRICH, A. S. Transformações químicas da matéria orgânica durante a compostagem de resíduos da indústria madeireira. Química Nova, Vol. 27, No. 3, 399-403, 2004.

CAMPOS, A. E. L.; NUNES, G. S.; OLIVEIRA, J. C. S.; TOSCANO, I. A. S. Avaliação da contaminação do Igarapé do Sabino (Baciado Rio Tibiri) por metais pesados, originados dos resíduos e efluentes do Aterro da Ribeira, em São Luís, Maranhão. Química Nova. Vol. 32, No. 4, 960-964, 2009.

COMPANHIA DE TECNOLOGIADE SANEAMENTO AMBIENTAL CETESB. 2006. Relatório de Qualidade Ambiental do Estado de São 
Paulo, São Paulo, SP.

CORDEIRO, R. et al. A Inadequação dos Valores dos Limites de Tolerância Biológica para a Prevenção da Intoxicação Profissional pelo Chumbo no Brasil. Caderno Saúde Pública, RJ, 11 (2), p. 177-186, abr/jun. 1995.

CRESCÊNCIO JÚNIOR, F. Estudo de turfas em laboratório como barreira reativa na remediação de aquíferos. Tese apresentada à COPPE/UFRJ para a obtenção do grau de Doutor em Ciências. Rio de Janeiro, 2008.

DA SILVA, A. C.; MENDONÇA, E. D. S. Modelo fractal de substâncias húmicas. Ciência Rural, Santa Maria, v.31, n.5, p.903-908, 2001.

DANTAS, S. T.; SARON, E. S.; DANTAS, F. B. H.; YAMASHITA, D. M, KIYATAKA, P. H. M. Determinação da dissolução de alumínio durante cozimento de alimentos em panelas de alumínio. Ciênc. Tecnologia de Alimentos. Campinas, 27(2): 787-792, abr.-jul. 2007.

DE SAUSSURE, T. Recherches chemiques sur la végetation. Paris, 1804. apud STEVENSON, F. Journal Humus Chemistry. New York, Wiley, 1982. p. 26-53.

DUARTE, R. S. Avaliação de metais pesados: Cádmio (Cd), Chumbo (Pb), Zinco (Zn) e Níquel (Ni) em cabelos humanos. Omnia Saúde. I, p. 7 - 17, 2004.

E- ESCOLA. Instituto Superior Técnico. Disponível em: http://www.eescola.pt/topico. asp?id=496\&ordem=8. Acessado em Junho, 2009. Publicado em 28/10/2008.

FERREIRA, A. D. Q. O impacto do crômio nos sistemas biológicos. Química Nova, Vol. 25, No. 4, 572-578, 2002.

FERREIRA, J. C.; ZINI, J.; SCARPIN, M. A.; Carvalho, F. M. S.; Abrão, A.; Anais do $3^{\circ}$ Congresso Brasileiro de Gestão Ambiental e Desenvolvimento Sustentável, São Pedro, Brasil, 2006.

FERREIRA, P. C.; PIAI, K.A.; TAKAYANAGUI, A. M. M.; MUÑOZ, S. I. S. Alumínio como fator de risco para a doença de Alzheimer. Revista Latino-Am. 
Enfermagem. 16(1) janeiro-fevereiro, 2008.

FREITAS, T. C. M. O cromo na indústria de curtumes de Mato Grosso do Sul, Brasil: Aspectos ecológicos. Tese de doutorado. Programa Multiinstitucional de Pós Graduação em Ciências da Saúde. Campo GrandeMS, 2006.

GIESEKINGI, J. E. Soil components: organic components. New York, Springer, 1975 apud In: CARDOSO, E. J. B. N.; TSAI, S. M.; NEVES, M. C. P. Microbiologia do solo. Campinas, Sociedade Brasileira de Ciência do Solo, 1992. p. 73-89.

HAYES, M. H. B. Humic substances: progress towards more realistic concepts of structures. In: DAVIES, G., GHABBOUR, E. A., ed.. Humic substances: structures, properties and uses. Cornwall: MPG Books, 1998. 259p.

ICZ. Instituto de Metais não Ferrosos. Disponível em http://www.icz.org.br/ niquel-saude.php. Acessado em Setembro, 2009.

JUNIOR, R.; ALVES, G. A saúde do trabalhador o contato com os metais. Universidade Federal Fluminense UFF. Trabalho de conclusão de curso. Niterói; 2006. $42 \mathrm{p}$.

KLÖCKING, R. Humic substances as potential therapeutics, in: SENESI, N.; MIANO, T. (Eds), Humic Substances in the Global Environmental and Implications on Human Health, Elsevier, Amsterdam, 1994, pp. 1245-1257.

KONONOVA, M.M. Soil organic matter: its nature, its role in soil formation and in soil fertility. 2.ed. Oxford, Pergamon Press, 1966. 544 p.

KYSIOL, J. Effect of Physical Properties and Cátion Exchange Capacity on Sorption of Heavy Metals onto peats - Polish Journal of Environmental Studies, v.11, n. 6, p. 713-718. 2002.

LARINI, L.; 1993. Toxicologia. Editora Manole. Segunda Edição.

LEVIGARD, Y. E. A interpretação dos profissionais de saúde acerca das queixas de nervoso no meio rural - uma aproximação ao problema das 
intoxicações por agrotóxicos. Dissertação de Mestrado. Fundação Oswaldo Cruz . Escola Nacional De Saúde Pública. Rio de Janeiro, 2001.

MALCOLM, R. The uniqueness of humic substances in each of soil, stream and marine environments. Analytica Chimica Acta, v. 232, p. 19-30, 1990.

\section{MAVROPOULOS, E. A hidroxiapatita como absorvedor de metais.}

Dissertação de Mestrado. Fundação Oswaldo Cruz, Escola Nacional de Saúde Pública; 1999. 105 p. Disponível em <http://portalteses.icict.fiocruz.br/ transf.php?script=thes chap\&id=00006603\&lng=pt\&nrm=iso. $>$ Acesso em 17 de agosto de 2009.

MERTZ, W. Chromium in human nutrition: a review. J. Nutr., Philadelphia, v. 123, n. 4, p.626-633, Apr. 1993. Disponível em: <http://jn.nutrition.org/cgi/ reprint/123/4/626.pdf>. Acesso em: 5 jul. 2009.

NASCIMENTO, S. C.; HYPOLITO, R.; RIBEIRO, A. A. Disponibilidade de metais pesados em aterro de indústria siderúrgica. Engenharia sanitária ambiental. Vol.11 - No 3 - jul/set 2006, 196-202.

OLENDZKI, R. N. Caracterização das interações de substâncias húmicas com a matéria inorgânica em solos de cultivo de arroz irrigado: contribuição à aquisição de dados essenciais para avaliação global do seqüestro de carbono no solo. Tese de Doutorado para obtenção de título de doutor em Química, Curso de Pós-Graduação em Química, Setor de Ciências Exatas, Universidade Federal do Paraná. Curitiba, 2006.

PICCOLO, A. \& SPITELLER, M. Electrospray ionization mass spectrometry of terrestrial humic substances and their size fractions. Anal. Bioanal. Chem., 377:1047-1059, 2003.

PICCOLO, A. The Supramolecular structure of humic substances: A novel understanding of humus chemistry and implications in soil science. Adv.Agron., 75:57-134, 2002.

QUINTELAS, C. M. C. Recuperação e reutilização de metais pesados. Dissertação para obtenção do grau de mestre em biotecnologia. Universidade do Minho. Escola de Engenharia. Departamento de Engenharia Biológica. Braga, 2000. 
ROCHA, J. C.; ROSA, A. H. Substâncias húmicas aquáticas: interação com espécies metálicas. São Paulo, Editora UNESP, 2003. 138 p.

ROCHA, J. C.; ROSA, A.A., CARDOSO, A. A. Introdução à Química Ambiental. Porto Alegre: Bookman, 2009. 230p.

ROCHA, J. C.; TOSCANO, I. A. S.; BURBA, P. Lability of heavy metal species in aquatic humic substances characterized by ion exchange whith cellulose phosphate. Talanta, v. 44, p. 69-74, 1997a.

ROCHA, J. C.; TOSCANO, I. A. S.; CARDOSO, A. A. Relative lability of trace metals complexed in aquatic humic substances using ion-exchanger cellulosehyphan. Journal of the Brazilian Chemical Society, v. 8, p. 239-243, 1997 b.

\section{ROSA, A. H. Desenvolvimento de metodologia para extração de} substâncias húmicas de turfas utilizando-se hidróxido de potássio.

Dissertação de Mestrado. Universidade Estadual Paulista - UNESP. Instituto de Química. Araraquara, 1998.99p.

ROSEMA, T. Toxicidade de metais em humanos. Revista de Oxidologia. Ano VII. n.6. Nov/Dez 1998.

SANO, H.; KATO, Y.; TAKEBAYASHI, A.; SHIGA, A. Effects of supplemental chromium and isolation stress on the tissue responsiveness and sensitivity to insulin in sheep. Small Ruminant Research, v.33, p.239-246, 1999.

SANTOS, A.; BELLIN, I. C.; CORBI, P.P.; CUIN, A.; ROSA, A. H.; REZENDE, M.O.O.; ROCHA, J.C.; MELNIKOV, P. Competition Between Humic Substances and ?-Amino Acids by Metal Species. Journal Chemical Society. Vol 15. $n^{\circ} 3.437-440.2004$.

SANTOS, A.; BOTERO, W.G.; BELLIN, I. C.; OLIVEIRA, L. C.; ROCHA, J.C.; MENDONCA, A. G. R.; GODINHO, A.F. Interaction between Humic Substances and Metallic Ions: a Selectivity Study of Humic Substances and their Possible Terapeutic Application. . J. Braz Chem. Soc. Vol 18. n 4, 2007.

SANTOS, G. C. G.; RODELLA, A. A. Efeito da adição de fontes de matéria 
orgânica como amenizantes do efeito tóxico de B, Zn, cu, Mn e Pb no cultivo de brassica juncea. R. Bras. Ci. Solo, 31:793-804, 2007.

SCHNITZER, M.; KHAN, S. U. Soil organic matter. Amsterdan, Elsevier, 1978. 319p.

SEIXAS, T. G.; AMARAL, I. M.; KEHRIG, H.; MALM, O. Distribuição de selênio em organismos marinhos da Baía de Guanabara/ RJ. Química Nova, Vol. 30, No. 3, 554-559, 2007.

SILVA, V. C.; JUCA, M. C. A.; MONTEIRO, C. M. B. E. ; OLIVEIRA, E. A. Intoxicações por chumbo: alerta para cuidados com acidentes na infância.

Revista de Pediatria. 8(2): 91-4, jul./dez. 2007.

STEVENSON, F. J. Cycles of soil. Carbon, nitrogen, phosphorus, sulphur, micronutrients. New York, Jonh Willey, 1985. 380 p.

STEVENSON, F. J. Humus chemistry. New York, Wiley, 1982. p. 26 - 53.

STEVENSON, F. J. Humus chemistry: genesis, composition and reaction, 2.ed. New York, John Wiley, 1994. 496 p.

TROMBE, A.C. Agentes complexantes de chumbo, cádmio e mercúrio para uso em casos de intoxicação. Monografia de conclusão de curso apresentada no Instituto de Química. UNESP Araraquara. 1994.

WAKSMAN, S. A. Humus. Baltimore: Wilians and Wilkins, 1936. apud In: STEVENSON, F. J. Extraction, fractionation, and general chemical composition of soil organic matter. Humus chemistry. New York, Wiley, 1982. p. 26-53.

WERSHAW, R. L. Model for humus in soils and sediments. Environmental Science Technology, v. 27, p. 814-816, 1993.

ZINI, J. ; FERREIRA, J. C.; CARVALHO, F. M. S.; BUSTILLOS, J. O. W.V.; SCAPIN, M. A.; SALVADOR, V. L. R; ABRÃO, A. Estudo de metais e de substâncias tóxicas em brinquedos. Química Nova, Vol. 32, No. 4, 833838, 2009. 


\section{Title: Humic Substances: Possibility of New Therapeutic Application}

\section{ABSTRACT}

Humic substances (HS) are heterogeneous molecular aggregates, which have no defined structure and constitute the principal fraction of natural organic matter. They can act as complexation agents, due to their high density of functional groups, and therefore directly influence the transport, accumulation, bioavailability and toxicity of different substances. Metals are important environmental pollutants, since they are widely used during human activities, and following release are not either chemically or biologically degraded. Treatment of acute poisoning in humans caused by potentially toxic metals has employed complexation agents such as ethylenediaminetetraacetic acid (EDTA) or $\alpha$-aminoacids. However, some limitations of these materials such as the lack of selectivity of EDTA and the high cost of $\alpha$-aminoacids have provided the incentive for a search for alternatives. Previous studies of the properties of $H S$ indicate their possible use as an alternative to these chelanting agents.

KEYWords: Humic substances; Potentially toxic metals; Chelating agents. 